\title{
Folliculogenesis during the transitional period and early ovulatory season in mares
}

\author{
O. J. Ginther \\ Department of Veterinary Science, University of Wisconsin-Madison, Madison, Wisconsin 53706, \\ $U S A$
}

\begin{abstract}
Summary. Individual follicles were monitored by ultrasonography in 15 mares during the transitional period preceding the first ovulation of the year and in 9 mares during the first interovulatory interval. During the transitional period, 7 mares developed 1-3 anovulatory follicular waves characterized by a dominant follicle (maximum diameter $\geq 38 \mathrm{~mm}$ ) that had growing, static, and regressing phases. The emergence of a subsequent wave (anovulatory or ovulatory) did not occur until the dominant follicle of the previous wave was in the static phase. After the emergence of the subsequent wave, the previous dominant follicle regressed. The mean ( \pm s.d.) length of the interval between successive waves was $10 \cdot 8 \pm 2 \cdot 2$ days. Before the emergence of waves (identified by a dominant follicle), follicular activity seemed erratic and follicles did not reach $>35 \mathrm{~mm}$. During the interovulatory interval, 6 mares developed 2 waves (an anovulatory wave and a subsequent ovulatory wave) and 3 mares developed only 1 detected wave (the ovulatory wave). The ovulatory follicle at the end of the transitional period reached $20 \mathrm{~mm}$ earlier (Day -15$)$, grew slower $(2.6 \pm 0.1 \mathrm{~mm} /$ day; mean \pm s.e.m.) but reached a larger diameter on Day $-1(50.5 \pm 1 \cdot 1 \mathrm{~mm})$ than for the ovulatory follicle at the end of the interovulatory interval (Day $-10,3.6 \pm 0.2 \mathrm{~mm} /$ day, $44.4 \pm 1.0 \mathrm{~mm}$, respectively; $P<0.05$ for each end point). The interval from cessation of growth of the largest subordinate follicle to the occurrence of ovulation was longer $(P<0.05)$ for end of the transitional period $(9.5 \pm 0.7$ days) than for the end of the interovulatory interval $(6.8 \pm 0.6$ days). Results demonstrated the occurrence of rhythmic follicular waves during some transitional periods and the occurrence of 2 waves during some of the first oestrous cycles of the year.
\end{abstract}

Keywords: follicles; follicular waves; mares; reproductive seasonality

\section{Introduction}

Follicular activity in mares is suppressed during the months of short daylength (anovulatory season). As daylength increases, the average number and diameter of follicles increase over 2 or 3 months (transitional period) until ovulation occurs. During the transitional period, follicles grow and regress sequentially (Ginther, 1979). During the oestrous cycle, the mean profile for diameter of largest follicle, as determined by ultrasonography, was found to be unimodal (Pierson \& Ginther, 1987). However, large preovulatory-sized follicles and sometimes an ovulation may develop in the first half of dioestrus (Stabenfeldt et al., 1972; Vandeplassche et al., 1979), indicating that substantial follicular activity may sometimes occur during the first part of the oestrous cycle before the activity that gives rise to the ovulatory follicle. Two waves of follicular activity during the oestrous cycle have been suggested in mares, primarily on the basis of bimodal FSH profiles (Evans \& Irvine, 1975). In heifers, ultrasonic monitoring of individual ovarian follicles indicated that most oestrous cycles have 2 (Pierson \& Ginther, 1988; Ginther et al., 1989a) or 3 (Savio et al., 
1988; Sirois \& Fortune, 1988) waves of follicular activity. Waves occurred periodically until the corpus luteum regressed, and in the absence of luteolysis (pregnant heifers) the periodicity continued (Ginther et al., 1989b). Each wave involved the emergence of several follicles. One follicle of the first postovulatory wave became dominant and grew to an average of $16 \mathrm{~mm}$ within 6 days, remained at an apparent plateau for approximately 6 more days, and then regressed. The dominant follicle of the 2 nd or 3 rd wave became the ovulatory follicle. For heifers, it has been proposed that a dominant follicle during its growing phase suppresses not only its subordinates but also the emergence of other waves and causes regression of the static dominant follicle of the preceding wave (Ginther et al., 1989b). These effects are apparently exerted through systemic and not local intraovarian channels (Ginther et al., 1989c).

The purpose of the present study was to monitor individual follicles in mares by transrectal ultrasonography to determine whether follicular waves occur during the transitional period and to determine whether the characteristics of the waves are similar to those that occur in cattle during the oestrous cycle and pregnancy. In addition, examination was made of follicular waves during the first interovulatory interval of the year.

\section{Materials and Methods}

The animals were riding-type horse mares $4-20$ years of age and weighed $400-500 \mathrm{~kg}$. Breeds were not known. However, the mares appeared to be primarily of Quarter Horse and Appaloosa breeding based on size, conformation, and colour patterns. All mares were non-lactating and in good body condition. They were kept under natural daylength. Mares were not used if they had apparent ovarian or uterine abnormalities based on transrectal ultrasonic inspection. Ultrasonic examinations of the ovaries and uterus were done as described by Ginther (1986) with a realtime, linear-array scanner equipped with $5 \mathrm{mHz}$ intrarectal transducer (Tokyo Keiki LS-200H, Tokyo Keiki USA, Chatsworth, CA, USA).

Daily ultrasonic examinations were initiated on 10-26 March 1988 in 19 mares. Mares that ovulated within 30 days of the start of examinations were excluded. This was done to minimize the possibility of including mares that had already ovulated before the examinations began. Size of follicles was based on an average of width and height. Location of follicles was indicated on an ovarian sketch, using landmarks that included the ovulation fossa, cranial and caudal ovarian poles, greater curvature of the ovary, and relative positions among follicles and luteal structures. The sketch from only the previous day was consulted at each examination. As many follicles as possible were individually identified. Uterine echotexture was recorded as being characteristic of oestrus, non-oestrus, or intermediate (Ginther, 1986).

Teasing of mares for oestrous behaviour was done by leading a stallion to a mare in the examining chute. Behaviour was recorded as being characteristic of oestrus, non-oestrus, or intermediate. However, behavioural testing was not initiated until 6 April. The day of ovulation for single ovulators and the day of the second ovulation in double ovulators was designated Day 0. Nine mares that were examined during the transitional period were also examined daily during the first interovulatory period. The diameter and location of only the largest and second largest follicle were recorded consistently for each ovary, but an attempt was made to identify all follicles $\geq 20 \mathrm{~mm}$ except when a large number of follicles precluded individual identification. Uterine echotexture, but not sexual behaviour, was determined on each day of the interovulatory interval.

The diameters of individual follicles were plotted and inspected for wave patterns. After inspection of data, a dominant follicle for the transitional period was defined as an anovulatory follicle that reached at least $38 \mathrm{~mm}$ or an ovulatory follicle (end of transitional period). Subordinate follicles were defined as those that appeared to originate from the same wave as a dominant follicle but regressed before reaching $35 \mathrm{~mm}$. The interval between successive waves was defined as the number of days between dominant follicles during the growing phase when the dominant follicles reached $30 \mathrm{~mm}$. After data inspection, the interovulatory intervals were classified into those that had 1 wave (ovulatory wave) and 2 waves (an anovulatory wave during the first half of the interovulatory interval and an ovulatory wave during the second half). The dominant follicle of one-wave intervals and the dominant follicle of the second wave in two-wave intervals were defined as the dominant ovulatory follicle. Other follicles that appeared to originate in a given wave were defined as subordinates.

Growth rate of the ovulatory follicle was compared for single ovulators between ovulation at the end of transition (first ovulation of the year) and ovulation at the end of the first interovulatory interval (second ovulation of the year). The slope for each follicle was determined by regression analysis and the slopes were compared between the 2 groups. Comparisons were also made between groups by analysis of variance for the following end points: (1) diameter of preovulatory follicle on the day before ovulation, (2) length of interval from cessation of growth of the largest subordinate follicle to ovulation of the dominant follicle, and (3) diameters of the dominant ovulatory and subordinate follicles on the day the largest subordinate ceased to grow. 

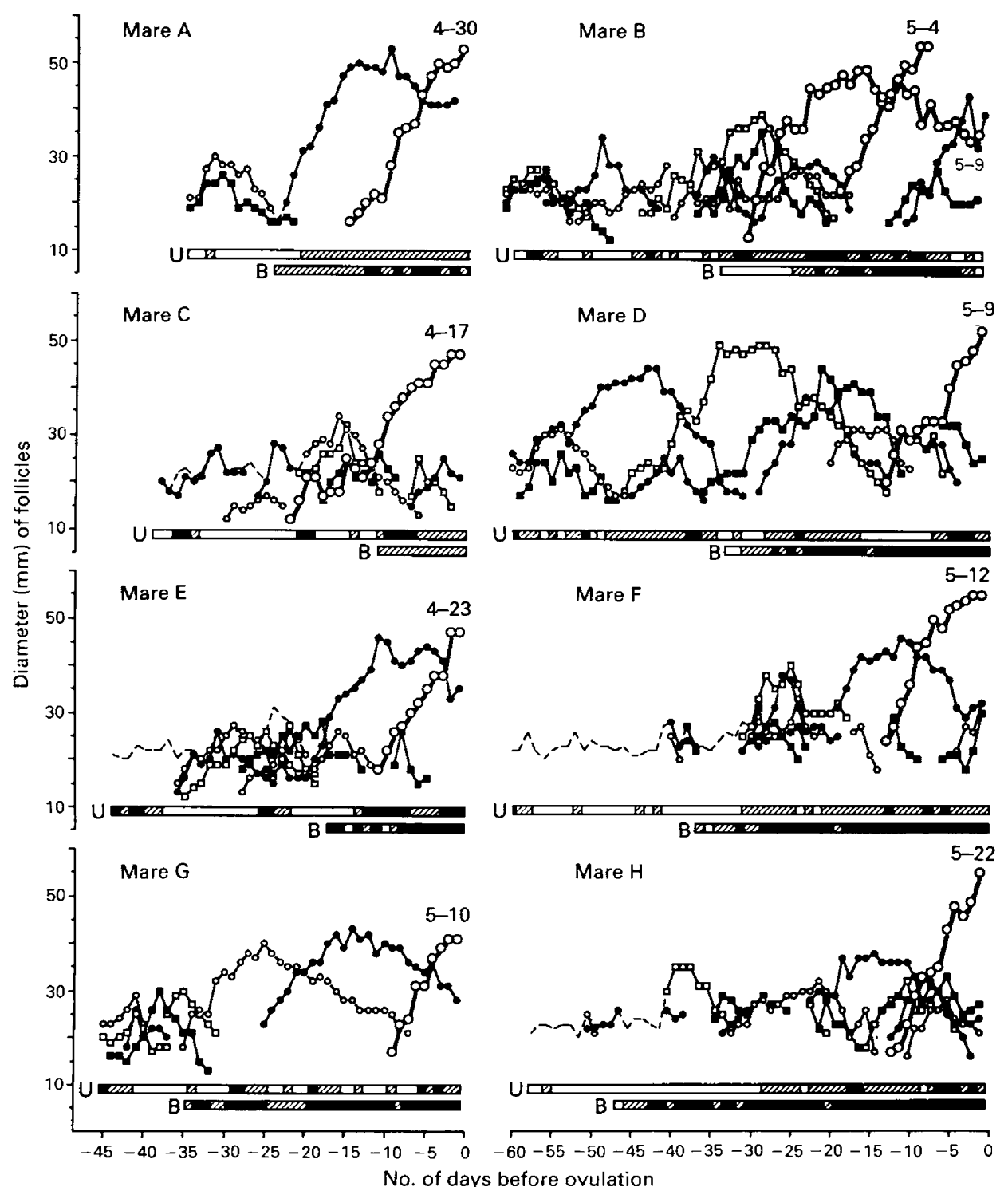

Fig. 1. Diameters of individual follicles for Mares A-H during the transitional period. The ovulatory follicles are indicated by heavy black lines and large circles. The date of ovulation is indicated. The broken lines without symbols (Mares C, E, F, H) represent the diameter of largest follicle when individual identity of the largest follicle was not feasible. The bars beneath each mare's follicular profiles are for uterine echogenicity (U) and sexual behaviour (B). For both bars, white is non-oestrous-like, black is oestrous-like, and hatched is for intermediate. The large anovulatory dominant follicle present on the day of ovulation in Mares A, E, G continued to regress during the interovulatory interval (not shown). The outcome of the waves that began to emerge just before Day 0 is shown in Fig. 4.

\section{Results}

The interval from the first examination to the first ovulation was $<13$ days in 3 mares and these mares were excluded. Another mare was excluded because the number of follicles was so great that 

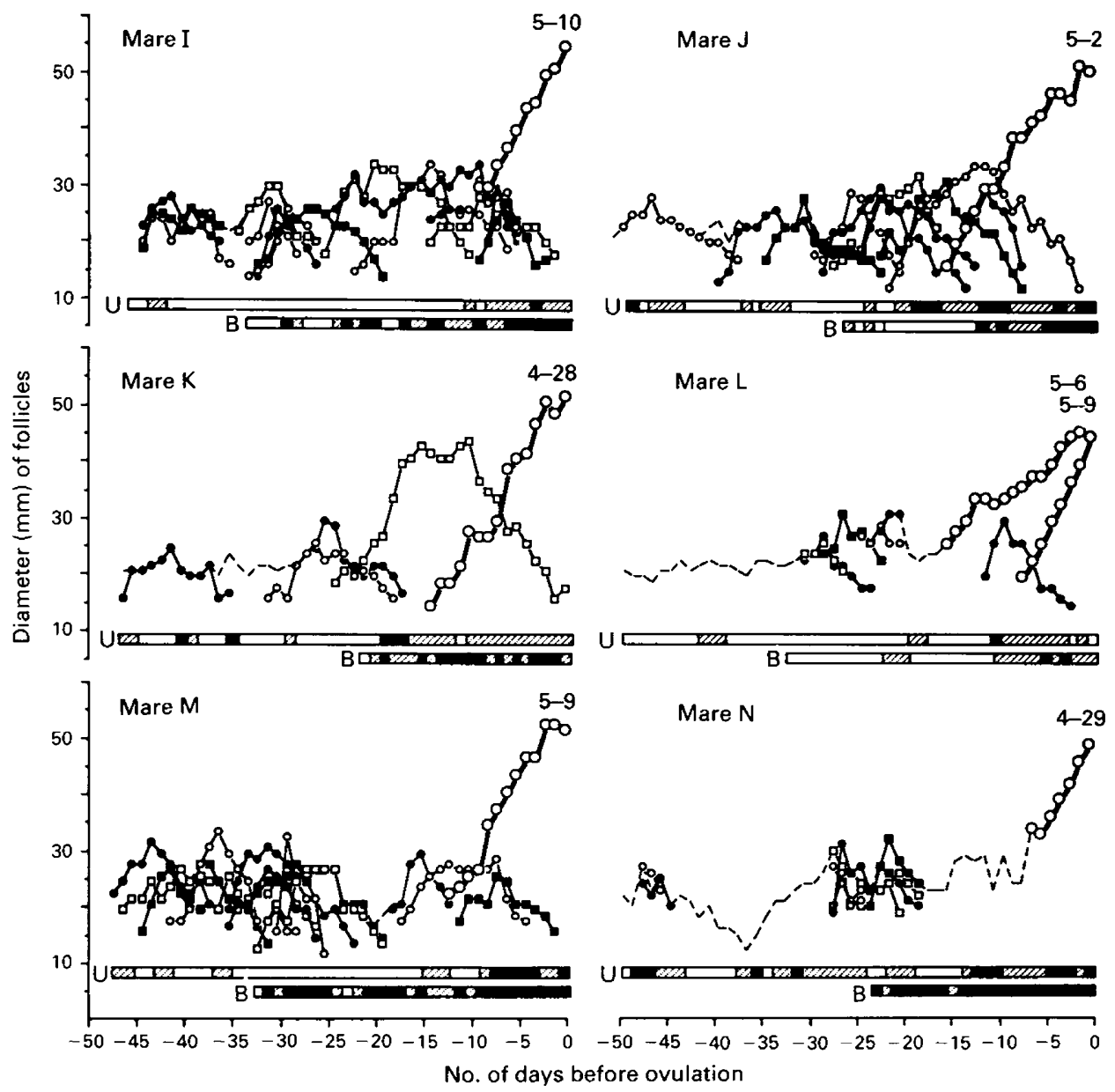

Fig. 2. Diameters of individual follicles for Mares I-N during the transitional period. Ovulatory follicles are indicated by heavy black lines and large circles. The date of ovulation is indicated. The broken lines without symbols (Mares J, K, L, M, N) represent the diameter of largest follicle when individual identity of the largest follicle was not feasible. The bars beneath each mare's follicular profiles are for uterine echogenicity (U) and sexual behaviour (B). For both bars, white is non-oestrous-like, black is oestrous-like, and hatched is for intermediate.

day-to-day identification was not feasible (13-26 follicles of $15-23 \mathrm{~mm}$ per ovary). This mare showed oestrous behaviour for 35 consecutive days before ovulating and an oestrous uterine echotexture for 9 days before ovulating. The individual follicular profiles for the transitional period in the remaining 15 mares are shown (Figs 1, 2, 3). In 7 of 15 mares, identification of individual follicles was not feasible on some days because of large numbers of follicles in an ovary. The diameter of the largest follicle for these periods is shown (broken line; Figs 1, 2; Mares C, E, F, H, $\mathrm{K}, \mathrm{L}, \mathrm{N}$ ). The number of $15-23 \mathrm{~mm}$ follicles per ovary on these days ranged from 8 to 17 . In addition, in 12 of the 15 mares some follicles of $15-19 \mathrm{~mm}$ were not individually identifiable on some days. The follicular patterns in Mare $O$ (Fig. 3) appeared different from that in the other mares; the interval between the growing phases of 2 large $(>40 \mathrm{~mm})$ anovulatory follicles was 40 days, and the interval between growing phases of the last anovulatory follicle and the ovulatory follicle was 37 days. In addition, Mare $\mathrm{O}$ did not ovulate until 23 June, 1 month after the last of 


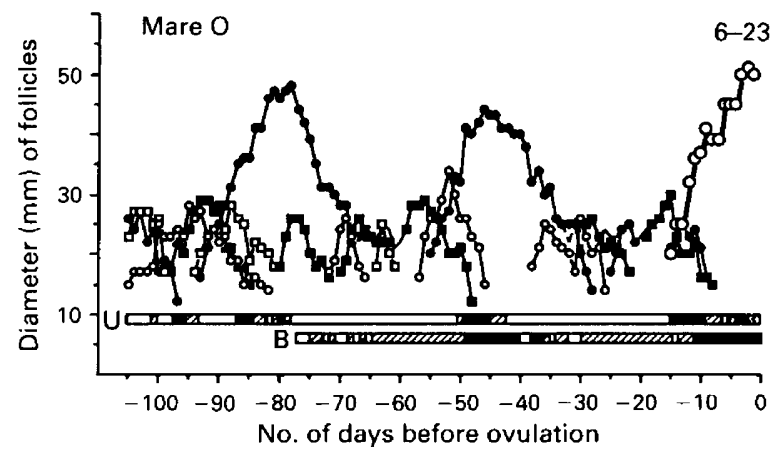

Fig. 3. Diameters of individual follicles for Mare $O$ during the transitional period. Ovulatory follicles are indicated by heavy black lines and large circles. The date of ovulation is indicated. The bars beneath the profile are for uterine echogenicity (U) and sexual behaviour (B). For both bars, white is non-oestrous-like, black is oestrous-like, and hatched is for intermediate.

the other 14 mares had ovulated. This mare was not further considered in the characterization calculations.

During the transitional period, 8 of the remaining 14 mares $(\mathrm{A}, \mathrm{B}, \mathrm{D}-\mathrm{H}, \mathrm{K})$ had 1-3 anovulatory follicles that exceeded $38 \mathrm{~mm}$. These follicles $(n=12)$ and the ovulatory follicles $(n=16)$ were designated as dominant follicles. The 16 ovulatory follicles include both ovulations in 2 mares that double ovulated $(\mathrm{B}, \mathrm{L})$. Each anovulatory dominant follicle appeared to consist of a growing, static, and regressing phase. The number of days between successive dominant follicles (anovulatory and ovulatory) was $10 \cdot 8 \pm 2 \cdot 2$ days (mean \pm s.d.; $n=12$ ). The follicular dynamics preceding the emergence of the first wave (identified by a dominant follicle) did not involve obvious wave patterns. In the remaining 6 mares $(\mathrm{C}, \mathrm{I}, \mathrm{J}, \mathrm{L}-\mathrm{N})$, none of the anovulatory follicles exceeded $35 \mathrm{~mm}$ in diameter. In these 6 mares, a wave pattern was not apparent until the ovulatory wave appeared. Apparent subordinate follicles were detected for 15 of 28 follicular waves.

During the interovulatory intervals, 1 apparent follicular wave was detected in 3 mares (Fig. 4; $A, I, J)$ and 2 apparent waves were detected in 6 mares (B-D, F, G, K). In the mares with 2 waves, the first wave began before the first ovulation of the year $(B, F)$ or shortly thereafter $(C, D, G, K)$. The dominant follicle of the first wave of two-wave interovulatory intervals exceeded $25 \mathrm{~mm}$ in all mares, but none ovulated (dioestrous ovulation). Apparent subordinate follicles were detected in association with 10 of 15 follicular waves. The largest subordinate follicles reached $25-35 \mathrm{~mm}$ and then regressed. Two mares (A, D) formed haemorrhagic follicles. In Mare A, the follicle developed floating echogenic specks at the time of an expected primary ovulation (Days 18-20) and a network of echogenic bands formed on Day 21. The haemorrhagic follicle grew to a maximum of $87 \mathrm{~mm}$ and then regressed (not shown). In Mare D, a large follicle developed during the first half of the interovulatory interval and formed floating echogenic specks on Days 10 and 11 after it reached $40 \mathrm{~mm}$. Echogenic bands formed on Day 13, and on the same day the emergence of the second or ovulatory wave was identified, retrospectively. The haemorrhagic follicle collapsed while being examined on Day 15.

The growth rate of the ovulatory follicle at the end of the transitional period $(2 \cdot 6 \pm 0 \cdot 1 \mathrm{~mm} /$ day $)$ was less $(P<0.001)$ than for the growth rate at the end of the interovulatory interval $(3.6 \pm 0.2 \mathrm{~mm} /$ day; Fig. 5). However, the preovulatory follicle on Day $-1(50.5 \pm 1.1 \mathrm{~mm})$ was larger $(P<0.001)$ for the end of the transitional period than for the end of the interovulatory interval $(44.4 \pm 1.0 \mathrm{~mm})$. The average day at which the ovulatory follicle reached $20 \mathrm{~mm}$ was earlier for the transitional period (Day - 15) than for the interovulatory interval (Day - 10; Fig. 5). The interval from cessation of growth of the largest subordinate follicle to the occurrence of ovulation was longer $(P<0.05)$ for the end of the transitional period $(9.5 \pm 0.7$ days $)$ than for the end of the 

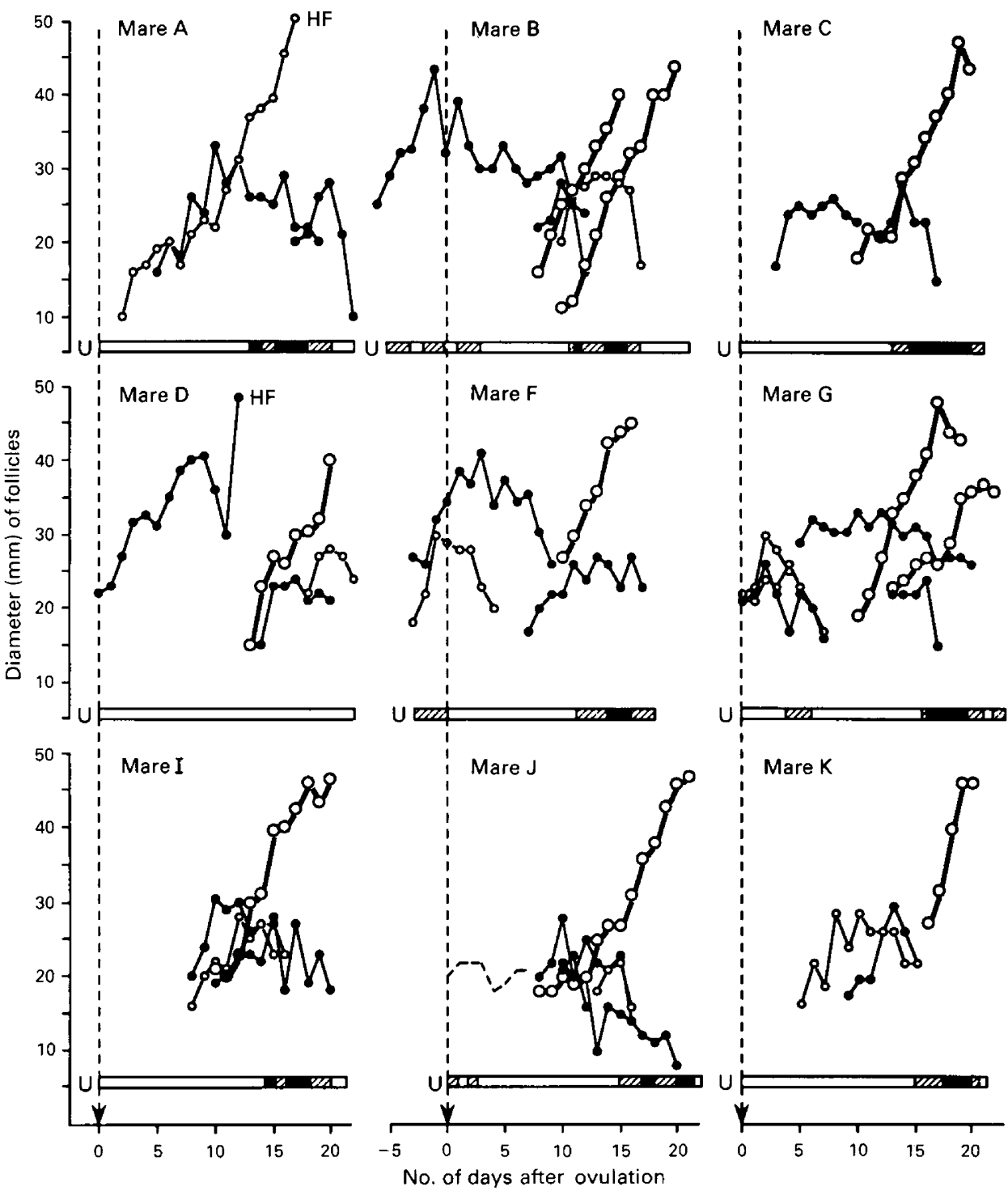

Fig. 4. Diameters of individual follicles during the first interovulatory interval. The identification letters (A-D, F, G, I-K) refer to the identification of mares depicted in Figs 1 and 2. HF indicates that the follicle developed echogenic bands characteristic of clotted blood. Refer to legend of Fig. 1 for further explanation. Mares A, I, and J appear to have 1 wave of follicular activity and the remainder appear to have 2 waves.

interovulatory interval $(6 \cdot 8 \pm 0.6$ days; Table 1$)$. However, the diameters of the dominant follicle and the subordinate follicle on the day of growth cessation were not different between the first and second ovulations of the year.

\section{Discussion}

During the transitional period, anovulatory follicular waves were not manifest until a follicle reached $38 \mathrm{~mm}$. Follicular waves (anovulatory and ovulatory) seemed similar to follicular waves in 


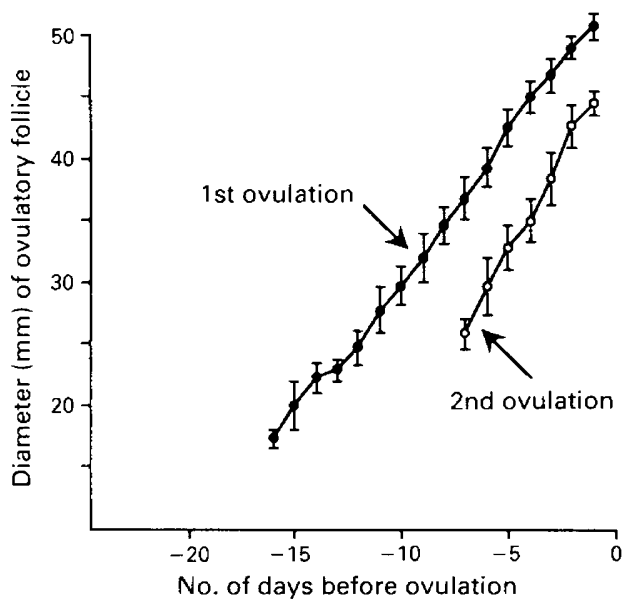

Fig. 5. Sequential diameters of follicle that resulted in the first ovulation of the year (end of transitional period) and the follicle that resulted in the second ovulation (end of first interovulatory interval). The follicle involved in the first ovulation was identified earlier, grew at a slower rate and reached a greater diameter on Day -1 than the follicle involved in the second ovulation $(P<0.05$ for each end point $)$.

Table 1. Relationships (mean \pm s.e.m.) between the dominant ovulatory follicle and the largest subordinate follicle on the day of cessation of growth of the subordinate

\begin{tabular}{|c|c|c|}
\hline & $\begin{array}{c}\text { First } \\
\text { ovulation* }\end{array}$ & $\begin{array}{c}\text { Second } \\
\text { ovulation* }\end{array}$ \\
\hline $\begin{array}{l}\text { Interval from } \\
\text { cessation of growth } \\
\text { of the subordinate } \\
\text { follicle to ovulation } \\
\text { (days)** } \\
\text { Diameters on day } \\
\text { subordinate follicle } \\
\text { ceased to grow }(\mathrm{mm})\end{array}$ & $9 \cdot 5 \pm 0.7$ & $6 \cdot 8 \pm 0.6$ \\
\hline $\begin{array}{l}\text { Dominant follicle } \\
\text { Subordinate follicle }\end{array}$ & $\begin{array}{l}30 \cdot 8 \pm 1 \cdot 1 \\
28 \cdot 0 \pm 0 \cdot 8\end{array}$ & $\begin{array}{l}29 \cdot 1 \pm 1 \cdot 1 \\
27 \cdot 2 \pm 1 \cdot 1\end{array}$ \\
\hline
\end{tabular}

cattle except that the follicles were much larger in mares. In most waves associated subordinate follicles were detected. Dominant anovulatory follicles had growing, static, and regressing phases, and emergence of another wave (anovulatory or ovulatory) was not detected while the dominant follicle was in its growing phase. Initiation of regression of a static-phase anovulatory dominant follicle was not evident until after emergence of a new wave. Follicular activity before the first detected wave of the transitional period seemed erratic (no obvious pattern); the follicles grew and regressed but did not exceed $35 \mathrm{~mm}$. In retrospect, the growth and regression profiles of individual follicles for the transitional period, obtained previously by transrectal palpation (Ginther, 1979), are consistent with the profiles found in the present ultrasound study; the studies differ primarily in detail. 
On the basis of the above findings, the following over-all hypothesis is suggested for testing. During the transitional period, follicles grow and regress until one reaches a critical size (e.g. $40 \mathrm{~mm}$ ). The large follicle either ovulates or anovulatory follicular waves develop sequentially until conditions are right for ovulation. The dominant follicle of each wave causes the demise of its subordinates and blocks the emergence of another wave until the dominant follicle reaches a static phase (anovulatory wave) or approaches ovulation (ovulatory wave). Another wave then emerges which contributes to regression of the dominant follicle of the previous anovulatory wave or, if ovulation has occurred, the new wave becomes the first wave of the first interovulatory interval.

Perhaps large follicles produce substances that have a regulatory role in follicular periodicity; smaller follicles do not produce adequate quantities of such substances and wave-like patterns are not obvious. The suppressing substances may be inhibin and oestrogen. In this regard, a proteinaceous fraction of follicular fluid (containing inhibin?) suppressed circulating FSH and follicular development in mares (Bergfelt \& Ginther, 1985), and the proteinaceous fraction combined with oestradiol had a greater FSH-suppressing action in ovariectomized mares than did the proteinaceous fraction alone (Miller et al., 1981). Production of oestrogen by the large follicles is consistent with the oestrus-like uterine echotexture which seemed approximately related to the growing phase of large follicles (Figs 1, 2, 3,4). Behavioural oestrus during the transitional period seemed to be a less critical indicator and was sometimes present for greatly prolonged periods. Perhaps during the transitional period the suppressing substances reduce circulating FSH concentrations while the large follicle is in its growing phase. This assumption is consistent with periodic FSH waves seen in individual mares during transition (Ginther, 1979). Presumably, the reduction in FSH is involved in cessation of growth of a dominant follicle (anovulatory wave); the anovulatory-wave phenomenon terminates when adequate $\mathrm{LH}$ is available to ovulate a dominant follicle. Direct comparisons of follicular patterns with circulating concentrations of $\mathrm{FSH}$ and $\mathrm{LH}$ during the transitional period are needed.

The larger size of the Day -1 preovulatory follicle before the first ovulation than before the second agrees with the results of an earlier study (Pierson \& Ginther, 1987). In addition, the first ovulatory follicle grew more slowly than the second. These results may be related to the report that the LH profile at the second and later ovulations is more pronounced than at the first (Freedman et al., 1979a).

Two $(\mathrm{B}, \mathrm{L})$ of 15 mares double ovulated at the end of the transitional period. In both mares, the ovulatory follicles seemed to originate from different waves. In one of these mares (B), the second ovulation occurred from the previous dominant follicle while it was in its regressing phase (decreasing in diameter). Based on ultrasonic examinations, the resulting collapsed follicle formed an illdefined corpus luteum that seemed much smaller than other corpora lutea. The decreasing diameter of the preovulatory follicle and lack of a well-defined corpus luteum indicated that this follicle collapsed while it was undergoing atresia. A similar phenomenon, collapse of follicles while undergoing apparent atresia, has been reported by Sirois et al. (1989).

Of the 9 interovulatory intervals, 2 waves were detected in 6 mares and only one wave (the ovulatory wave) was detected in the remaining 3 mares. In an earlier study, follicles were measured ultrasonically regardless of day-to-day identity (Pierson \& Ginther, 1987); this approach resulted in a unimodal follicular profile, but the first wave of 2-wave intervals may have been masked by the averaging procedure. The first wave in the two-wave intervals was prominent (dominant follicle, $>35 \mathrm{~mm}$ ) in 3 mares $(\mathrm{B}, \mathrm{D}, \mathrm{F})$, but dioestrous ovulations did not occur. The incidence of dioestrous ovulations in mares that were similar to the mares used in the present study has been reported to be only $4 \%$ ( 3 of 69 interovulatory intervals; Ginther \& Pierson, 1989). In other breeds (e.g. Thoroughbreds), the incidence of dioestrous ovulations is considerably higher (Stabenfeldt $e t$ al., 1972), presumably because some breeds have more follicular activity during the first half of dioestrus than others. Time of year also affects the extent of follicular activity during the first half of dioestrus. Means for diameter of largest follicle (regardless of individual identity) during the first 
half of dioestrus were approximately $23-25 \mathrm{~mm}$ in May to July and $15-18 \mathrm{~mm}$ in August to October (Pierson \& Ginther, 1987). The present study was for the first interovulatory interval of the year, and perhaps the observed number of 2-wave intervals was higher than would occur later in the year. In this regard, FSH concentrations in pony mares have been reported to be bimodal early in the ovulatory season and unimodal (low during first half of dioestrus) late in the season (Ginther, 1979).

Two mares (Figs $1 \& 2 ; \mathrm{B}, \mathrm{F}$ ) began a detectable wave after the first ovulatory wave began but before ovulation. In both mares the wave continued into the interovulatory interval (Fig. 4) and developed into a prominent anovulatory early dioestrous wave. Cattle also occasionally begin a detectable wave before the occurrence of ovulation (Ginther et al., 1989a).

At the end of the interovulatory intervals, double ovulations occurred in 2 mares (Fig. 4; B, G). It is not clear whether the 2 follicles originated from the same wave, but in Mare G one follicle grew at a slower rate, resulting in asynchronous ovulations. Haemorrhagic follicles occurred in two mares (Fig. 4; A, D); this condition has been described (Ginther, 1979; Ginther \& Pierson, 1984) and is apparently (not adequately demonstrated) associated with ovulatory failure. The haemorrhagic follicle developed during oestrus in Mare A and during dioestrus in Mare D. Mare A had a double ovulation 24 days after formation of the haemorrhagic follicle. The 2 follicles grew at the same rate and ovulated synchronously.

The cessation of growth of subordinate follicles a mean of 6.8 days before the second ovulation supports the conclusion that selection of the ovulatory follicle during the ovulatory season becomes manifest early in oestrus (transrectal palpation; Ginther, 1979) or by Days -6 or -7 (transrectal ultrasonography; Pierson \& Ginther, 1987). Cessation of growth of subordinates occurred earlier before the first ovulation than before the second ovulation. These findings are compatible with the report of Freedman et al. (1979b); at the onset of the ovulatory season, the preovulatory decline in plasma FSH concentrations reached significance by Day -12 , whereas during the middle of the ovulatory season the decline occurred by Day -8 . Apparently selection of the ovulatory follicle becomes manifest shortly after FSH concentrations begin to decline (Ginther, 1979).

After completion of this study, Sirois et al. (1989) reported on the monitoring of individual mare follicles by daily ultrasonography during 17 oestrous cycles. One wave of follicles was detected in 12 cycles and 2 waves in 5 cycles. Length of oestrous cycles was shorter for mares with one wave ( 18.2 days) than for mares with 2 waves ( 21.6 days). No such tendency was noted in the present study, but the number of observations was small.

In conclusion, waves of follicular development, characterized by the rhythmic growth and regression of large $(\geq 38 \mathrm{~mm}$ ) dominant follicles, were detected in 8 of 14 mares during the transitional period before the first ovulation of the year. Before the emergence of the anovulatory follicular waves in these mares and before the ovulatory wave in the remaining mares, follicular growth and regression occurred without an apparent pattern and follicles did not develop to $>35 \mathrm{~mm}$. The study also confirmed the occurrence of 1 or 2 follicular waves during the first oestrous cycle.

Supported by the College of Agricultural and Life Sciences, University of Wisconsin-Madison and by Equiculture, Inc., Cross Plains, Wisconsin. I thank Lisa Kulick and Roger Pierson for technical assistance and Maria Westphal for manuscript preparation.

\section{References}

Bergfelt, D.R. \& Ginther, O.J. (1985) Delayed follicular development and ovulation following inhibition of FSH with equine follicular fluid in the mare. Theriogenology 24, 99-108.

Evans, M.J. \& Irvine, C.H.G. (1975) Serum concentrations of FSH, LH and progesterone during the oestrous cycle and early pregnancy in the mare. $J$. Reprod. Fert., Suppl. 23, 193-200.

Freedman, L.J., Garcia, M.C. \& Ginther, O.J. (1979a) Influence of ovaries and photoperiod on reproductive function in the mare. J. Reprod. Fert., Suppl. 27, $79-86$. 
Freedman, L.J., Garcia, M.C. \& Ginther, O.J. (1979b) Influence of photoperiod and ovaries on seasonal reproductive activity in mares. Biol. Reprod. 20, $567-574$.

Ginther, O.J. (1979) Reproductive Biology of the Mare: Basic and Applied Aspects, 417 pp. Equiservices, Cross Plains, Wisconsin.

Ginther, O.J. (1986) Ultrasonic Imaging and Reproductive Events in the Mare, $378 \mathrm{pp}$. Equiservices, Cross Plains, Wisconsin.

Ginther, O.J. \& Pierson, R.A. (1984) Ultrasonic evaluation of the reproductive tract of the mare: ovaries. $J$. equine Vet. Sci. 4, 11-16.

Ginther, O.J. \& Pierson, R.A. (1989) Regular and irregular characteristics of ovulation and the interovulatory interval in mares. J. equine Vet. Sci. 9, 4-12.

Ginther, O.J., Knopf, L. \& Kastelic, J.P. (1989a) Temporal associations among ovarian events in cattle during oestrous cycles with two and three follicular waves. $J$. Reprod Fert. 87, 223-230.

Ginther, O.J., Knopf, L. \& Kastelic, J.P. (1989b) Ovarian follicular dynamics in heifers during early pregnancy. Biol. Reprod. 41, 247-254.

Ginther, O.J., Kastelic, J.P. \& Knopf, L. (1989c) Intraovarian relationships among dominant and subordinate follicles and the corpus luteum in heifers. Theriogenology 32, 787-795.

Miller, K.F., Wesson, J.A. \& Ginther, O.J. (1981) Interaction of estradiol and nonsteroidal follicular fluid substance in the regulation of gonadotropin secretion in the mare. Biol. Reprod. 24, 354-358.

Pierson, R.A. \& Ginther, O.J. (1987) Follicular population dynamics during the estrous cycle of the mare. Anim. Reprod. Sci. 14, 219-231.

Pierson, R.A. \& Ginther, O.J. (1988) Ultrasonic imaging of the ovaries and uterus in cattle. Theriogenology 29, 21-37.

Savio, J.D., Keenan, L., Boland, M.P. \& Roche, J.F. (1988) Pattern of growth of dominant follicles during the oestrous cycle in heifers. J. Reprod. Fert. 83, $663-671$.

Sirois, J. \& Fortune, J.E. (1988) Ovarian follicular dynamics during the estrous cycle in heifers monitored by real-time ultrasonography. Biol. Reprod. 39, 308-317.

Sirois, J., Ball, B.A., \& Fortune, J.E. (1989) Patterns of growth and regression of ovarian follicles during the oestrous cycle and after hemiovariectomy in mares. Equine vet. J. Suppl. 8, 43-48.

Stabenfeldt, G.H., Hughes, J.P. \& Evans, J.W. (1972) Ovarian activity during the estrous cycle of the mare. Endocrinology 90, 1379-1383.

Vandeplassche M., Henry, M. \& Coryn, M. (1979) The mature mid-cycle follicle in the mare. J. Reprod. Fert., Suppl. 27, 157-162.

Received 9 February 1990 